\title{
PENGARUH KESEIMBANGAN, DAYA LEDAK OTOT TUNGKAI, DAN MOTIVASI BERPRESTASI DENGAN KEMAMPUAN TENDANGAN MONTHONG DOLIOCHAGI
}

\author{
Yudabbirul Arif ${ }^{1}$, Lukas M. Boleng ${ }^{2}$, V.M.M. Flora Babang ${ }^{3}$, Khetye R Saba ${ }^{4}$ \\ ${ }^{1234}$ Universitas Nusa Cendana, Kupang, Indonesia, \\ e-mail: yudabbirul@staf.undana.ac.id
}

\begin{abstract}
Abstrak
Penelitian ini bertujuan dan melihat serta untuk mengetahui ada atau tidaknya pengaruh langsung antara aspek keseimbangan, serta daya ledak otot tungkai dan motivasi berprestasi dengan kemampuan tendangan monthong doliochagi pada atlet taekwondo. Penelitian ini dilakukan pada Atlet Taekwondo Kota Padang Panjang. Pengambilan sampel dilakukan dengan menggunakan teknik sampel total Purposive sampling sebanyak 35 orang. Pengujian hipotesis pengaruh langsung keseimbangan terhadap kemampuan tendangan monthong doliochagi sebesar 0,369 . Pengaruh langsung antara aspek daya ledak otot tungkai terhadap kemampuan tendangan monthong doliochagi sebesar 0,374 . Pengaruh langsung antara motivasi berprestasi terhadap kemampuan tendangan monthong doliochagi sebesar 0,298. Kemudian pengaruh langsung antara aspek keseimbangan terhadap motivasi berprestasi sebesar 0,336. Pengaruh langsung antara aspek daya ledak otot tungkai terhadap motivasi berprestasi sebesar 0,410. Hasil penelitian menyimpulkan terdapat pengaruh lanusng antara keseimbangan, daya ledak otot tungkai dan motivasi berprestasi terhadap kemampuan tendangan monthong doliochagi pada atlet taekwondo kota Padang panjang..
\end{abstract}

Kata kunci: daya ledak otot tungkai, keseimbangan, tendangan monthong doliochagi, motivasi berprestasi.

\begin{abstract}
The purpose of this study was to determine whether or not the direct influence of balance, leg muscle explosive power and achievement motivation on the ability Monthong kick doliochagi. The object of this of this Research was conducted on Taekwondo Athletes Padang Panjang. Sampling was done by using purposive sampling technique total sample. Hypothesis Testing the hypothesis balance influence on the ability monthong doliochagi kick at 0.369. Effect of leg muscle explosive power to kick monthong doliochagi ability of 0.374 . The influence of achievement motivation on the ability monthong doliochagi kick at 0.298. The influence of the balance of the achievement motivation of 0.336. Effect of leg muscle explosive power against motivasii excel at 0.410. The study concluded there is positive between balance, leg muscle explosive power and achievement motivation on the ability of the athlete kicks taekwondo monthong doliochagi Padang Panjang city.
\end{abstract}

Keywords : leg muscle explosive power, balance, Monthong doliochagi kick, achievement motivation 


\section{Pendahuluan}

Faktor olahraga sangat mempunyai perananan penting dalam membentuk kehidupan bermasyarakat. Aktifitas kebugaran fisik yang teratur dapat memperbaiki kesegaran jasmani sehingga badan dapat berfungsi secara efisien dan optimal untuk melakukan tugas seharihari. Bompa mengatakan dalam tim dasar-dasar penjas adalah bentuk-bentuk kegiatan jasmani yang terdapat dalam permainan, perlombaan, dan kegiatan jasmani yang intensif dalam rangka rekreasi, kemenangan dan prestasi optimal (Tim Dasar-Dasar Penjas, ,2011:33). Olahraga saat ini yang lagi berkembang pesat salah satunya adalah olahraga beladiri Taekwondo, baik di dunia maupun di Indonesia.

Jika melihat-lihat prestasi Taekwondo Kota Padang Panjang dalam rentang waktu 3 tahun belakangan ini dapat dilihat bahwa Pengcab Taekwondo Padang Panjang kurang berprestasi di berbagai even, karena tidak dapat dicapainya target yang dicanangkan pengcab. Berdasarkan perkembangan ilmu dan teknologi, pada zaman ini diharapkan kepada seluruh insan masyarakat pendidik/ pelatih yang nantinya mampu memberikan suatu perubahan baru agar dapat meningkatkan perkembangan prestasi, baik dalam disiplin ilmu pendidikan maupun prestasi olahraga.

Faktor mengapa tendangan monthong doliochagi kebanyakan di gunakan taekwondoin karena pertama tendangan ini tidak terlalu menyerap energi, kedua tendangan ini memiliki kecepatan diatas rata-rata tendangan lainnya, ketiga tendangan ini sangat lah fleksibel, maksudnya bisa dikombinasikan dengan tendangan lain maupun dengan menggunakan step-step, keempat tendangan ini sangat lah praktis bisa digunakan saat terdesak. Kelima teknik ini sangatlah mudah dilakukan.

Dalam pemikiran filosofis, filosofis oriental dari Do telah dipakai untuk menandakan perilaku filosofis tentang tangan dan kaki yang tidak terpisahkan dari terminologi Taekwondo, (Kyong Myong Lee dalam Yoyok Suryadi,2008:19). Dalam olahraga beladiri taekwondo, tubuh seseorang dapat dibagi dalam tiga aspek bagian, yang mana mengacu pada arae (bagian tubuh dibawah), momtong (batang tubuh) dan momtong (perut), kemudian olgul (wajah).

Teknik dasar gerakan-gerakan Taekwondo lebih banyak dimainkan dengan menggunakan kaki/ pertarungan atas (standing fighting), tetapi bukan berarti tidak diajarkan gerakan-gerakan tangan.( Bellavia Ariestia Dofi,2010:3). Seperti kutipan diatas bisa disimpulkan bahwa bisa kita lihat bahwa Taekwondo lebih banyak menggunakan kaki dalam latihannya, karena taekwondo lebih mengutamakan teknik kaki dalam bertarung.

Di dalam taekwondo, penggunaan tendangan sangat dominan, terdapat berbagai variasi tendangan taekwondo, semua harus dilakukan dengan kecepatan dan ketepatan tinggi.(Gugun Arief Gunawan, 2007:32). Keseimbangan atau balance adalah kemampuan yang sangat diperlukan oleh seseorang baik itu sebagai olahragawan maupun bukan seorang olahragawan dalam melakukan kegiatan sehari-hari.

Dikatakan Most sports skills involve a force that can disrupt the balance of the body, generated from the movement of a limb. When hitting a tennis ball, swinging a bat, or kicking a soccer ball, the torque and angular momentum of the limb and implement will tend to rotate the body in opposition to the limb movement. (Jeffrey Willardson 2013 : 31). Sebagaimana yang dikatakan kutipan diatas bahwa sebagian besar olahraga yang melibatkan kekuatan sangat cendrung untuk mengganggu keseimbangan tubuh disaat melakukan keterampilan itu berbeda halnya jika dia sudah menguasai teknik dan bisa memberikan power di tiap teknik yang dilakukan.

Jika seseorang bergerak dengan seimbang maka itu bisa diartikan melakukan koordinasi dan control dalam bergerak. Keseimbangan merupakan koordinasi dan control. (Gerry Carr dalam Taufik Yudi Mulyanto dan Johansyah Lubis, 2009:89) Saat melakukan aktifitas gerak diperlukan berbagai macam faktor, dari kekuatan, kecepatan, bahkan keseimbangan yang berkesinambungan dengan semua anggota tubuh kita.

Keseimbangan merupakan sebuah kemampuan mempertahankan sikap dan posisi tubuh secara tepat pada saat berdiri (static balance) atau pada saat melakukan gerakan (dynamic balance). (Widiastuti, 2011 :144). Menurut kutipan diatas keseimbangan 
merupakan bagian yang tidak dapat dipisahkan dalam kemampuan gerak dasar dan merupakan salah satu komponen dalam mempemgaruhi keberhasilan atlet untuk menguasai teknik dalam olahraga beladiri taekwondo.

terdapat dua jenis tipe dalam keseimbangan yaitu keseimbangan saat diam dan keseimbangan saat bergerak, tergantung saat dimana penggunaannya. Keseimbangan bisa diklafikasikan menjadi 2 macam yaitu keseimbangan statis dan keseimbangan dinamik.(Budi Indrawan, 2012: 88). Keseimbangan statis adalah kemampuan seseorang bergerak di atas dasar yang sempit seperti contoh saat berdiri di balok keseimbangan, berdiri di rel kereta api, melakukan handstand, untuk mempertahankan keseimbangan di putar beberapa putaran di tempat berdiri. Keseimbangan dinamik (dynamic balance) adalah merupakan kemampuan seseorang untuk bergerak dari satu titik atau ruang ke lain titik atau ruang lain dengan mempertahankan keseimbangan (equilibrium), seperti menari, latihan pada kuda-kuda atau palang sejajar, ski air, skating, sepatu roda dan lainnya.

Daya ledak merupakan suatu komponen fisik yang sangat dibutuhkan dalam olahraga beladiri taekwondo maupun berbagai cabang olahraga lainnya. Daya ledak sebagai produk dari dua kemampuan yaitu kekuatan (strength) dan kecepatan (speed) untuk melakukan force maksimum dalam waktu yang sangat cepat. (Bompa dalam Syafrudin, 2011:102).

Otot rangka bagian bawah dalam posisi anterior terdiri dari: adductor group (practineus, addutor longus, gracils), quadriceps femoris group (sartorius, rectus femoris, vastus medialis, vastus lateralis), peroneus longus, extensor digitorum longus, tibialis anterior, gastrocnemius, soleus. Otot rangka bagian bawah posisi posterior terdiri dari: hamstring group (biceps femorls, semitendinosus, semimabranosus), gastrocnemius, achilles (calcaneal) tebdon, gluteus medius, gluteus maximus, adductor magnus, gracilis, vastur lateralis, sartorius,soleus dan peroneus longus (James tangkudung, 2006:36).

Dalam daya ledak otot tungkai terdapat kekutan merupakan salah satu faktor penting yang harus dipunyai saat terjadinya daya ledak yaitu kekuatam. The relationship between intensity and volume is not straightforward. Typically, as you increase intensity, you will decrease volume, and vice versa. Training at a high volume, with lots of reps and sets performed with comfortable weights, is an excellent way to learn movements, but if you avoid more challenging loads you will not develop power and strength. (Bridle, Bob (Ed.) 2011: 19) Berdasarkan kutipan diatas dapat dipahami bahwa volume dan intensitas dari gerakan menentukan pengembangan dari segi kekuatan.

Kekuatan merupakan kemampuan dasar basis dari komponen kondisi, dikarenakan kekuatan merupakan daya penggerak setiap aktivitas fisik. Ada tiga hukum yang mendasari dalam latihan kekuatan, latihan pertama kembangkan fleksibilitas, kedua kembangkan kekuatan, dan ketiga kembangkan kekuatan pusat atau inti.

Motivasi yaitu dorongan yang timbul pada diri seseorang, sadar atau tidak sadar untuk melakukan suatu tindakan dengan tujuan tertentu (James Tangkudung, 2012:28). Dalam kutipan diatas dikatakan Motivasi merupakan sebagai suatu pendorong yang merubah energi dalam diri seseorang melalui motivasi kedalam bentuk aktifitas nyata untuk mencapai tujuan tertentu dalam target. Motivation for exercise could be physically or psychologically oriented (Bagchi, Debasis, Sreejayan Nair, Chandan K. Sen-Nutrition and Enhanced, 2013 : 66). Seperti kutipan diatas dijelaskan bahwa motivasi untuk berolahraga secara psikologis menentukan untuk hasil dari latihan tersebut, karena jika motivasi dalam berolahraga tinggi maka hasil yang akan di dapat dan target akan tercapai.

Motivasi dapat dijelaskan dan diartikan sebagai suatu dorongan dari dalam maupun dari luar, yang akan mengarahkan dan membentuk seseorang agar bisa melakukan suatu aktivitas yang sesuai dengan keinginan yang ingin dicapai dan target yang dicanangkan. Motivasi yang harus dimiliki oleh seorang atlet taekwondo adalah motivasi untuk berprestasi, sebab atlet yang memiliki motivasi berprestasi akan berpacu dan bersaing dengan keunggulan, baik keunggulan diri sendiri maupun keunggulan orang lain, bahkan untuk mencapai kesempurnaan dalam menjalankan latihan secara berkesinambungan maupun berkompetisi.

Motivasi berprestasi pada hakikatnya merupakan suatu keinginan, hasrat, kemauan, dan pendorong diri untuk dapat unggul yaitu mengungguli prestasi yang pernah dicapainya 
sendiri atau prestasi yang dicapai orang lain (Husdarta, 2010:25). Dari kutipan di atas dikatakan motivasi berprestasi yang tinggi tidak hanya dibutuhkan untuk pembinaan dan latihan teknik saja, tetapi juga diperlukan untuk semua proses pengurusan pembinaan untuk latihan dalam meraih suatu prestasi baik di daerah, nasional maupun di dunia internasional.

Tanpa dukugan dari aspek motivasi berprestasi yang tinggi dari seorang atlet taekwondo, maka akan sulit diharapkan tercapainya prestasi yang ingin dicapai. Untuk atlet taekwondo harus mempunyai motivasi yang kuat dalam mencapai prestasi dengan banyak upaya yang dapat dilakukan dan dicapai sampai meraih prestasi tersebut. Dalam meraih suatu prestasi bukanlah satu perkara yang mudah, untuk itu sangat membutuhkan proses agar semua dapat terealisasikan dengan baik dan disinilah sangat dibutuhkan motivasi berprestasi, dikarenakan jika seseorang yang tidak mempunyai motivasi berprestasi untuk meraih prestasi yang lebih tinggi maka dia tidak akan bisa melakukan aktiftas yang mendorong dirinya untuk berlatih secara berkelanjutan dan maksimal sehingga dapat mencapai tujuan yang telah di targetkan.

Berdasarkan penjabaran yang diatas, maka peneliti ingin melihat pengaruh langsung keseimbangan serta pengaruh langsung daya ledak otot tungkai serta motivasi berprestasi semua itu sebagai variabel bebasnya yang berpengaruh dengan variabel terikatnya. Serta tendangan monthong doliochagi sebagai variabel terikatnya (dependent variable). Tentunya dengan adanya penelitian ini akan membantu pelatih dalam melakukan evaluasi dalam teknik tendangan, agar bisa melakukan teknik tendangan yang benar dan tepat, maupun pengaruhnya dengan prestasi taekwondo Kota Padang Panjang, sehingga bisa meningkatkan prestasi Taekwondo Kota Padang Panjang untuk kedepannya.

\section{Metode}

Penelitian ini betujuan untuk mengungkap ada atau tidaknya pengaruh langsung dan tidak lansung antara keseimbangan, daya ledak otot tungkai dan motivasi berprestasi terhadap kemampuan tendangan monthong doliochagi pada atlet taekwondo kota padang panjang. Metode penelitian yang digunakan dalam penilitian ini merupakan metode kuatitatif asosiatif, dengan pendekatan kuantitatif, metode survei, dan model teknik analisi jalur (path analysis). Path analysis merupakan suatu teknik untuk menganalisis hubungan sebab akibat yang terjadi pada regresi berganda jika variabel bebasnya mempegaruhui variabel tergantung tidak hanya secara langsung tetapi juga secara tidak langsung. Instrumen tes kemampuan tendangan monthong dolio chagi menggunakan instrumen kemampuan tendangan monthong doliochagi.

Instrumen tes keseimbangan menggunakan tes stork stand (Widiastuti, 2011:144), selanjutnya untuk mengukur daya ledak otot tungkai menggunakan standing broad jump (widiastuti, 2011:105) dan instrumen motivasi berprestasi menggunakan instrumen tes berupa kuesioner dalam bentuk pertanyaan yang berpedoman pada skala likert yang diuji cobakan pada 20 atlet. Untuk melihat validitas menggunakan rumus product moment. Selanjutnya untuk melihat reliabelitas menggunakan rumus alpha cronbach. Data yang dikumpulkan akan dianalisis melalui uji persyaratan analisis yang terdiri dari uji normalitas dan uji homogenitas, kemudian uji Linearitas dan signifikan regresi, dan analisis jalur.

\section{Hasil dan Pembahasan}

\section{Hasil}

Penelitian ini dilakukan pada atlet taekwondo kota padang panjang. Populasi atlet taekwondo kota padang panjang adalah seluruh atlet taekwodo kota padang panjang. Pengambilan sampel dilakukan dengan menggunakan teknik porposive sampling, yang mana jumlah sampel 35 orang. Dalam penelitian deskripsi data dari hasil penelitian yang bertujuan untuk memberikan gambaran umum mengenai penyebaran distribusi data, baik yang berupa ukuran letak distribusi frekuensi. 
Penelitian ini meliputi variabel terikat yaitu: Kemampuan tendangan monthong doliochagi $(\mathrm{Y})$, dan 3 variabel bebas yaitu: Keseimbangan $\left(\mathrm{X}_{1}\right)$, Daya ledak otot tungkai $\left(\mathrm{X}_{2}\right)$ dan Motivasi Berprestasi $\left(X_{3}\right)$. Adapun data mentah penelitian memiliki satuan pengukuran yang berbeda, sehingga perlu diubah ke dalam skor T ( $t$-score). Bisa dilihat dari rangkuman hasil perhitungan statistik sebagai berikut :

\begin{tabular}{ccccc}
\hline STATISTIK & \multicolumn{4}{c}{ VARIABEL } \\
\cline { 2 - 5 } & $\mathbf{X}_{\mathbf{1}}$ & $\mathbf{X}_{\mathbf{2}}$ & $\mathbf{X}_{\mathbf{3}}$ & $\mathbf{Y}$ \\
\hline $\begin{array}{c}\text { Jumlah Sampel }(\mathrm{n}) \\
\text { Data terbesar }\end{array}$ & 35 & 35 & 35 & 35 \\
Data terkecil & 70,13 & 67,95 & 67 & 65,7 \\
Rentang & 27,58 & 31,36 & 27,8 & 24,1 \\
Rata-rata (r) & 42,55 & 36,59 & 39,2 & 41,6 \\
$\begin{array}{c}\text { Simpangan Baku (s) } \\
\left.\text { Varians (s }{ }^{2}\right)\end{array}$ & 50 & 50 & 50 & 50 \\
& 10 & 10 & 10 & 10 \\
& 100 & 100 & 100 & 100 \\
\hline
\end{tabular}

Berdasarkan data hasil penelitian statistik mengenai keseimbangan $\left(X_{1}\right)$, Daya ledak otot tungkai $\left(\mathrm{X}_{2}\right)$, Motivasi berprestasi $\left(\mathrm{X}_{3}\right)$, dan Kemampuan tendangan monthong doliochagi $(Y)$. Maka diperoleh data Keseimbangan $\left(X_{1}\right)$, Nilai terendah $=27,58$, tertingg $i=70,17$, rentang $=42,55$, modus $=33,63$, median $=48,5$, sedangkan rata-rata $=50$, dan simpangan baku $=10,00$ dan Varians $=100$.

Sedangkan, untuk daya ledak otot tungkai $\left(X_{2}\right)$, diperoleh data Nilai terendah $=31,36$, tertinggi $=67,95$, rentang $=36,59$, modus $=53,31$ median $=51,62$, sedangkan rata-rata $=$ 50,00 , dan simpangan baku $=10,00$, dan Varians $=99,99$. Berikutnya untuk data motivasi berprestasi $\left(X_{3}\right)$ diperoleh Nilai terendah $=27,8$, tertinggi $=67$, maka rentangnya $=39,2$, modus $=55,85$, median $=52,16$, sedangkan rata-rata $=50,00$, simpangan baku $=10,00$, dan Varians $=100$.

Terakhir untuk variable $\mathrm{Y}$ nya yang mana Kemampuan tendangan monthong doliochagi yaitu memiliki memiliki nilai terendah $=24,1$ tertinggi $=65,7$, sehinga memiliki rentang $=41,6$, modus $=50,54$ dan median $=50,54$. Sedangkan rata-rata $=50$ simpangan baku=10 dan Varians sebesar 100.

\section{Pembahasan}

Selanjutnya dilakukan uji normalitas yang mana dapat dilihat dari tabel berikut ini:

\begin{tabular}{ccrrl}
\hline Galat Taksiran & $\mathbf{N}$ & $\mathbf{L}_{\mathbf{0}}$ hitung & \multicolumn{2}{l}{$\mathbf{L}_{\mathbf{0}}$ tabel $a=$} \\
$\mathbf{0 , 0 5}$ & Kesimpulan \\
\hline Y atas $\mathbf{X}_{\mathbf{1}}$ & 35 & 0,063 & 0,150 & Normal \\
$\mathbf{Y}$ atas $\mathbf{X}_{2}$ & 35 & 0,096 & 0,150 & Normal \\
$\mathbf{Y}$ atas $\mathbf{X}_{\mathbf{3}}$ & 35 & 0,055 & 0,150 & Normal \\
$\mathbf{X}_{\mathbf{3}}$ atas $\mathbf{X}_{\mathbf{1}}$ & 35 & 0,069 & 0,150 & Normal \\
$\mathbf{X}_{\mathbf{3}}$ atas $\mathbf{X}_{\mathbf{2}}$ & 35 & 0,069 & 0,150 & Normal \\
\hline
\end{tabular}

Maka dilihat dari tabel diatas dapat kita jelaskan di kumpulkan berdistribusi normal atau tidak dengan hasil sebagai berikut:

a. Uji normalitas galat taksiran persamaan struktural kemampuan tendangan monthong doliochagi atas keseimbangan $\left(\mathrm{Y}\right.$ atas $\mathrm{X}_{1}$ ) Dalam persamaan struktural kemampuan 
tendangan monthong $(Y)$ terhadap keseimbangan $\left(X_{1}\right)$ adalah $Y=20,540+0,589 X_{1}$, dimana nilai kritis $a=0,05$ yang mana $n=35$, diperoleh $L_{\text {hitung }}$ sebesar 0,063 . Dimana nilai $L_{\text {tabel }}$ diperoleh nilai sebesar 0,150 jika dibandingkan nilai $L_{\text {hitung }}$ ternyata lebih kecil dari $L_{\text {tabel }}$ sehingga dapat disimpulkan diterima dan dinyatakan data berdistribusi normal.

b. Uji normalitas galat taksiran persamaan struktural kemampuan tendangan monthong doliochagi atas daya ledak otot tungkai $\left(\mathrm{Y}\right.$ atas $\mathrm{X}_{2}$ ). Dalam persamaan struktural kemampuan tendangan monthong $(\mathrm{Y})$ daya ledak otot tungkai $\left(\mathrm{X}_{2}\right)$ adalah $\mathrm{Y}$ $=19,494+0,610 \mathrm{X}_{2}$, dimana nilai kritis $a=0,05$ yang mana $n=35$, diperoleh $L_{\text {hitung }}$ sebesar 0,096 . Dimana nilai $L_{\text {tabel }}$ diperoleh nilai sebesar 0,150 jika dibandingkan nilai $L_{\text {hitung }}$ ternyata lebih kecil dari $L_{\text {tabel }}$ sehingga dapat disimpulkan diterima dan dinyatakan data berdistribusi normal.

c. Uji Uji normalitas galat taksiran persamaan struktural kemampuan tendangan monthong doliochagi atas motivasi berprestasi $\left(Y\right.$ atas $X_{3}$ ) Dalam persamaan struktural kemampuan tendangan monthong $(Y)$ terhadap motivasi berprestasi $\left(X_{3}\right)$ adalah $17,857+0,643 X_{3}$, dimana nilai kritis $a=0,05$ dan yang mana $n=35$, diperoleh $L_{\text {hitung }}$ sebesar 0,055 . Dimana nilai $L_{\text {tabel }}$ diperoleh nilai sebesar 0,150 jika dibandingkan nilai $L_{\text {hitung }}$ ternyata lebih kecil dari $L_{\text {tabel }}$ sehingga dapat disimpulkan diterima dan dinyatakan data berdistribusi normal.

d. Uji normalitas galat taksiran persamaan struktural motivasi berprestasi atas Daya ledak otot tungkai $\left(\mathrm{X}_{3}\right.$ atas $\left.\mathrm{X}_{1}\right)$ Dalam persamaan struktural kemampuan motivasi berprestasi $\left(X_{3}\right)$ terhadap Daya ledak otot tungkai $\left(X_{1}\right)$ adalah $X_{3}=28,234+0,435 X_{1}$, dimana nilai kritis $a=0,05$ yang mana $n=35$, diperoleh $L_{\text {hitung }}$ sebesar 0,069 . Dimana nilai $L_{\text {tabel }}$ diperoleh nilai sebesar 0,150 jika dibandingkan nilai $L_{\text {hitung }}$ ternyata lebih kecil dari $L_{\text {tabel }}$ sehingga dapat disimpulkan diterima dan dinyatakan data berdistribusi normal.

e. Uji normalitas galat taksiran persamaan struktural motivasi berprestasi atas daya ledak otot tungkai $\left(\mathrm{X}_{3}\right.$ atas $\left.\mathrm{X}_{2}\right)$ Dalam persamaan struktural kemampuan motivasi berprestasi $\left(X_{3}\right)$ terhadap Daya ledak otot tungkai $\left(X_{2}\right)$ adalah $X_{3}=25,422+0,492 X_{2}$, dimana nilai kritis $a=0,05$ yang mana $n=35$, diperoleh $L_{\text {hitung }}$ sebesar 0,069 . Dimana nilai $L_{\text {tabel }}$ diperoleh nilai sebesar 0,150 jika dibandingkan nilai $L_{\text {hitung }}$ ternyata lebih kecil dari $L_{\text {tabel }}$ sehingga dapat disimpulkan diterima dan dinyatakan data berdistribusi normal.

Kemudian dilakukan uji homogenitas untuk mengetahui varians dari populasi yang sama atau tidak, dengan hasil sebagai berikut:

a. Uji homogenitas $X_{1}$ terhadap $Y$

Dari data hasil perhitungan uji homogenitas varians Keseimbangan terhadap Kemampuan Tendangan Monthong doliochagi diperoleh nilai Chi $(X)$ Hitung sebesar 0,00 dan Chi Kuadrat $\left(X^{2}\right)$ tabel sebesar 3,38. Yang mana nilai $X$ hitung $<X^{2}$ tabel pada taraf signifikan 0,05 . Jadi dapat di ambil kesimpulan bahwa varians kelompok $X_{1}$ terhadap $Y$ memiliki varians yang Homogen.

b. Uji homogenitas $X_{2}$ terhadap $Y$

Dari data hasil perhitungan uji homogenitas varians Daya Ledak Otot Tungkai terhadap Kemampuan Tendangan Monthong doliochagi diperoleh nilai Chi $(X)$ Hitung sebesar 0,00 dan Chi Kuadrat $\left(X^{2}\right)$ tabel sebesar 5,99. Yang mana nilai $X$ hitung $<X^{2}$ tabel pada taraf signifikan 0,05 . Jadi dapat di ambil kesimpulan bahwa varians kelompok $X_{1}$ terhadap $Y$ memiliki varians yang Homogen. 
c. Uji homogenitas $X_{3}$ terhadap $Y$

Dari data hasil perhitungan uji homogenitas varians Motivasi berprestasi terhadap Kemampuan Tendangan Monthong doliochagi diperoleh nilai Chi $(X)$ Hitung sebesar 0,21 dan Chi Kuadrat $\left(X^{2}\right)$ tabel sebesar 9,49. Yang mana nilai $X$ hitung $<X^{2}$ tabel pada taraf signifikan 0,05. Jadi dapat di ambil kesimpulan bahwa varians kelompok $X_{1}$ terhadap $Y$ memiliki varians yang Homogen.

d. Uji homogenitas $X_{1}$ terhadap $X_{3}$

Dari data hasil perhitungan uji homogenitas varians Keseimbangan terhadap Motivasi berprestasi diperoleh nilai Chi $(X)$ Hitung sebesar 0,00 dan Chi Kuadrat $\left(X^{2}\right)$ tabel sebesar 3,84 . Yang mana nilai $X$ hitung $<X^{2}$ tabel pada taraf signifikan 0,05 . Jadi dapat di ambil kesimpulan bahwa varians kelompok $X_{1}$ terhadap $Y$ memiliki varians yang Homogen.

e. Uji homogenitas $X_{2}$ terhadap $X_{3}$

Dari data hasil perhitungan uji homogenitas varians Daya ledak otot tungkai terhadap Motivasi berprestasi diperoleh nilai Chi $(X)$ Hitung sebesar 0,89 dan Chi Kuadrat $\left(X^{2}\right)$ tabel sebesar 5,99 . Yang mana nilai $X$ hitung $<X^{2}$ tabel pada taraf signifikan 0,05 . Jadi dapat di ambil kesimpulan bahwa varians kelompok $X_{1}$ terhadap $Y$ memiliki varians yang Homogen.

Kemudian dilakukan uji linearitas regresi dan signifikan regresi sebagai pengujian persyaratan analisis yang menguji hubungan antar variabel dan keberartian regresi yang hasilnya sebagai berikut:

a. $\operatorname{Uji}\left(\mathrm{X}_{1}\right)$ terhadap $(\mathrm{Y})$

Berdasarkan hasil perhitungan uji linearitas regresi diperoleh harga $F$ (uji linearitas regresi) sebesar 0,09. Dimana nilai $F_{\text {tabel }}$ diperoleh nilai sebesar 250. Maka jika dibandingkan nilai $F_{\text {hitung }}$ ternyata lebih kecil dari $F_{\text {tabel, }}$, jadi dapat diambil kesimpulkan bahwa uji linearitas regresi $\mathrm{X}_{1}$ terhadapY berdistribusi linier. Kemudian jika dilihat uji keberartian regresi diperoleh harga $F$ sebesar 17,55. Dimana nilai $F_{\text {tabel }}$ diperoleh nilai sebesar 4,15. lalu dibandingkan dengan nilai $F_{\text {hitung }}$ ternyata lebih besar dari $F_{\text {tabel, }}$, sehingga dapat disimpulkan bahwa uji keberartian regresi $\mathrm{X}_{1}$ terhadapY berdistribusi cukup berarti.

b. $\operatorname{Uji}\left(\mathrm{X}_{2}\right)$ terhadap $(\mathrm{Y})$

Berdasarkan hasil perhitungan uji linearitas regresi diperoleh harga $\mathrm{F}$ (uji linearitas regresi) sebesar 2,15. Dimana nilai $F_{\text {tabel }}$ diperoleh nilai sebesar 5,77. Maka jika dibandingkan nilai $F_{\text {hitung }}$ ternyata lebih kecil dari $F_{\text {tabel, }}$ jadi dapat diambil kesimpulkan bahwa uji linearitas regresi $\mathrm{X}_{2}$ terhadapY berdistribusi linier. Kemudian jika dilihat uji keberartian regresi diperoleh harga $F$ sebesar 19,57. Dimana nilai $F_{\text {tabel }}$ diperoleh nilai sebesar 4,15. Ialu dibandingkan dengan nilai $F_{\text {hitung }}$ ternyata lebih besar dari $F_{\text {tabel }}$, sehingga dapat diambil kesimpulan bahwa uji keberartian regresi $X_{1}$ terhadapY berdistribusi cukup berarti.

c. Uji $\left(\mathrm{X}_{3}\right)$ terhadap $(\mathrm{Y})$

Berdasarkan hasil perhitungan uji linearitas regresi diperoleh harga $F$ (uji linearitas regresi) sebesar 1,22. Dimana nilai $F_{\text {tabel }}$ diperoleh nilai sebesar 2,38. Maka jika dibandingkan nilai $F_{\text {hitung }}$ ternyata lebih kecil dari $F_{\text {tabel, }}$, jadi dapat diambil kesimpulkan bahwa uji linearitas regresi $\mathrm{X}_{3}$ terhadapY berdistribusi linier. Kemudian jika dilihat uji keberartian regresi diperoleh harga $F$ sebesar 23,24. Dimana nilai $F_{\text {tabel }}$ diperoleh nilai sebesar 4,15. Ialu dibandingkan dengan nilai $F_{\text {hitung }}$ ternyata lebih besar dari $F_{\text {tabel }}$, sehingga dapat disimpulkan bahwa uji keberartian regresi $X_{3}$ terhadapY berdistribusi cukup berarti. 


\section{d. $\operatorname{Uji}\left(\mathrm{X}_{1}\right)$ terhadap $\left(\mathrm{X}_{3}\right)$}

Berdasarkan hasil perhitungan uji linearitas regresi diperoleh harga $F$ (uji linearitas regresi) sebesar 1,06. Dimana nilai $F_{\text {tabel }}$ diperoleh nilai sebesar 250. Maka jika dibandingkan nilai $F_{\text {hitung }}$ ternyata lebih kecil dari $F_{\text {tabel, }}$ maka dapat diambil kesimpulkan bahwa uji linearitas regresi $X_{1}$ terhadap $X_{3}$ berdistribusi linier. kemudian jika dilihat uji keberartian regresi diperoleh harga $F$ sebesar 7,72 . Dimana nilai $F_{\text {tabel }}$ diperoleh nilai sebesar 4,15. lalu dibandingkan dengan nilai $F_{\text {hitung }}$ ternyata lebih besar dari $F_{\text {tabel, }}$, sehingga dapat diambil kesimpulan bahwa uji keberartian regresi $X_{1}$ terhadap $X_{3}$ berdistribusi cukup berarti.

e. Uji $\left(\mathrm{X}_{2}\right)$ terhadap $\left(\mathrm{X}_{3}\right)$

Berdasarkan hasil perhitungan uji linearitas regresi diperoleh harga $F$ (uji linearitas regresi) sebesar 3,99. Dimana nilai $F_{\text {tabel }}$ diperoleh nilai sebesar 5,77. Maka jika

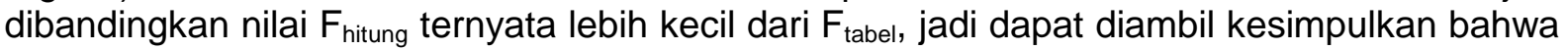
uji linearitas regresi $X_{1}$ terhadap $X_{3}$ berdistribusi linier. Kemudian jika dilihat uji keberartian regresi diperoleh harga $F$ sebesar 10,51. Dimana nilai $F_{\text {tabel }}$ diperoleh nilai sebesar 4,15. Ialu dibandingkan dengan nilai $F_{\text {hitung }}$ ternyata lebih besar dari $F_{\text {tabel }}$, sehingga dapat diambil kesimpulan bahwa uji keberartian regresi $\mathrm{X}_{2}$ terhadap $\mathrm{X}_{3}$ berdistribusi cukup berarti.

Setelah dilakukan uji persyaratan analisis selanjutnya dilakukan pengujian model dan pengujian hipotesis yang hasilnya sebagai berikut: pengaruh langsung Keseimbangan terhadap kemampuan tendangan monthong doliochagi sebesar 0,369. Pengaruh langsung daya ledak otot tungkai terhadap kemampuan tendangan monthong doliochagi sebesar 0,374 . Pengaruh langsung motivasi berprestasi terhadap kemampuan tendangan monthong doliochagi sebesar 0,298 . Pengaruh langsung Keseimbangan terhadap motivasi berprestasi sebesar 0,336 . Pengaruh langsung daya ledak otot tungkai terhadap motivasi berprestasi sebesar 0,410 .

\section{Simpulan dan Saran}

\section{simpulan}

terdapat pengaruh langsung antara Keseimbangan terhadap Kemampuan tendangan monthong doliochagi pada atlet taekwondo, terdapat pengaruh langsung antara daya ledak otot tungkai terhadap Kemampuan tendangan monthong doliochagi pada atlet taekwondo, terdapat pengaruh langsung antara motivasi berprestasi terhadap Kemampuan tendangan monthong doliochagi pada atlet taekwondo, terdapat pengaruh langsung antara Keseimbangan terhadap motivasi berprestasi dan terdapat pengaruh langsung antara Daya ledak otot tungkai terhadap motivasi berprestasi.

Implikasi dari penelitian yaitu seorang atlet taekwondo dalam melakukan kemampuan tendangan monthong doliochagi terdapat banyak faktor. Diantaranya merupakan keseimbangan, daya ledak otot tungkai, dan motivasi berprestasi, yang mana faktor ini amatlah penting bagi seorang atlet taekwondo. Dalam halnya kemampuan adanya suatu perbedaan yang dimiliki masing-masing atlet kemudian mengharuskan bagi tiap-tiap atlet untuk dapat dengan belajar dan berlatih secara terpogram dan terus menerus.

\section{Saran}

Berdasarkan kesimpulan hasil penelitian dan implikasi sebagaimana yang telah diuraikan diatas maka dapat disarankan, Kepada para Atlet, pembina dan pelatih taekwondo dalam meningkatkan kemampuan tendangan monthong doliochagi, keseimbangan, daya ledak otot tungkai dan motivasi berprestasi atlet taekwondo. Oleh karena itu kepada para atlet, pembina dan pelatih taekwondo agar selalu memperhatikan latihan-latihan yang dapat meningkatkan kemampuan dalam keseimbangan, daya ledak otot tungkai dan motivasi berprestasi, sehingga menghasilkan kemampuan tendangan monthong doliochagi yang baik, jadi para atlet harus mengikuti sesuai dengan program latihan yang sudah ada. Untuk para akademis olahraga supaya dapat melakukan penelitian untuk variabel-variabel lainnya yang 
dapat memberikan pengaruh langsung terhadap kemampuan tendangan monthong doliochagi

\section{Daftar Pustaka}

Bagchi, Debasis, Sreejayan Nair, Chandan K (2013). Performance Muscle Building, Endurance, and Strength. United States of America : Academic Press

Bridle, Bob (Ed.) (2011). Essential Strength Training Skills. China : L. Rex Printing Company Limited.

Carr, Gerry. (2009). Sport Mechanics For Coaches (second Edition). (terjemahan Taufik Yudi Mulyanto dan Johansyah Lubis). Jakarta : Pendidikan Olahraga PPS UNJ.

Dofi, Bellavia Ariestia. (2010). Seni Beladiri Taekwondo. Jakarta: Unit Kegiatan Mahasiswa Taekwondo.

Gunawan, Gugun Arief. (2007). Beladiri. Yogyakarta : Insan Mandiri.

Indrawan, Budi. (2011). Perkembangan Motorik Untuk Kalangan. Tasikmalaya : Universitas Siliwangi.

Suryadi, Vincentius Yoyok. (2008). The Book of WTF Poomsae Comprtiton / Poomsae Taekwondo Untuk Kompetisi. Jakarta: PT Gramedia Pustaka Utama.

Syafrudin (2011). Ilmu Kepelatihan Olahraga. Padang : Universitas Negeri Padang.

Tangkudung, James. (2006). Ilmu Faal (Fisiologi), Jakarta: Cerdas Jaya.

Tangkudung, James. (2012). Kepelatihan Olahraga, Jakarta: Cerdas Jaya.

Tim Dasar-Dasar Penjas. (2011). Dasar-Dasar Pendidikan Jasmani. Padang :FIK Universitas Negeri Padang : 2011.

Widiastuti. (2011). Tes dan Pengukuran Olahraga. Jakarta : PT Bumi Timur Jaya.

Willardson, Jeffrey. (2013). Developing the Core. United States of America : United Graphics. 